\title{
Vitamin D, high-sensitivity C-reactive protein, and airway hyperresponsiveness in infants with recurrent respiratory symptoms
}

\author{
Anette M. Määttä, MD*; Anne Kotaniemi-Syrjänen, MD*; Kristiina Malmström, MD*; \\ L. Pekka Malmberg, MD*; Jouko Sundvall, MSc ${ }^{\dagger}$; Anna S. Pelkonen, MD*; Mika J. Mäkelä, MD* \\ *Skin and Allergy Hospital, Helsinki University Hospital and University of Helsinki, Helsinki, Finland \\ ${ }^{\dagger}$ National Institute for Health and Welfare, Department of Health, Genomics and Biomarkers Unit, Helsinki, Finland
}

\section{A R T I C L E I N F O}

\section{Article history:}

Received for publication February 7, 2017.

Received in revised form June 21, 2017.

Accepted for publication June 23, 2017.

\section{A B S T R A C T}

Background: Vitamin D insufficiency might be associated with biased T-cell responses resulting in inflammatory conditions such as atopy and asthma. Little is known about the role of vitamin D in low-grade systemic inflammation and airway hyperresponsiveness (AHR) in young children.

Objective: To evaluate whether vitamin D insufficiency and increased serum high-sensitivity C-reactive protein (hs-CRP) are linked to AHR in symptomatic infants.

Methods: Seventy-nine infants with recurrent or persistent lower respiratory tract symptoms underwent comprehensive lung function testing and a bronchial methacholine challenge test. In addition, skin prick tests were performed and serum 25-hydroxyvitamin D (S-25-OHD), hs-CRP, total immunoglobulin E, and blood eosinophil levels were determined.

Results: S-25-OHD was lowest in infants with blood eosinophilia and AHR $(\mathrm{n}=10)$ compared with those with eosinophilia only $(n=6)$ or AHR only $(n=50)$ or those with neither $(n=13 ; P=.035)$. Moreover, vitamin D insufficiency (S-25-OHD $<50 \mathrm{nmol} / \mathrm{L}$ ) was most common in infants with blood eosinophilia and AHR $(P=.041)$. Serum hs-CRP was lower in infants with recurrent physician-diagnosed wheezing $(P=.048)$ and in those with blood eosinophilia $(P=.015)$ than in infants without these characteristics and was not associated with S-25-OHD or AHR. S-25-OHD levels were significantly lower (median $54 \mathrm{nmol} / \mathrm{L}$ ) during the autumn-winter season than in the spring-summer season (median $63 \mathrm{nmol} / \mathrm{L} ; P=.026$ ).

Conclusion: Vitamin D insufficiency could underlie eosinophilia and AHR in infants with troublesome lung symptoms, whereas hs-CRP-mediated low-grade systemic inflammation is rare in early childhood wheezing. (c) 2017 American College of Allergy, Asthma \& Immunology. Published by Elsevier Inc. All rights reserved.

\section{Introduction}

Evidence on the association between low serum vitamin D concentrations and asthma is currently inconsistent. ${ }^{1}$ In children with asthma, low vitamin D levels have been associated with decreased lung function ${ }^{2}$ and airway hyperresponsiveness (AHR), ${ }^{3,4}$ but there are contradictory results. ${ }^{1,5}$ In young wheezing children, vitamin D insufficiency has been linked to exacerbations requiring treatment with oral corticosteroids. ${ }^{6}$

High-sensitivity C-reactive protein (hs-CRP) is a biomarker reflecting low-grade systemic inflammation. A recent meta-analysis suggested that vitamin D supplementation decreases serum hs-CRP levels by $1 \mathrm{mg} / \mathrm{L}$ and that the effect is even more pronounced in adults with baseline hs-CRP levels of at least $5 \mathrm{mg} / \mathrm{L}^{7}$

Reprints: Anette M. Määttä, MD, Skin and Allergy Hospital, PO Box 160/1, FI-00029 HUS, Helsinki, Finland; E-mail: anette.m.maatta@helsinki.fi.

Disclosures: Authors have nothing to disclose.

Funding Sources: Foundation for Pediatric Research, Research Foundation of the Pulmonary Diseases, Finnish Medical Foundation, Sigrid Jusélius Foundation, Foundation for Allergy Research, and Ida Montin Foundation.
In schoolchildren with asthma, serum hs-CRP was higher than in their healthy peers, and a similar finding emerged between symptomatic steroid-free children and those who used inhaled corticosteroids. ${ }^{8}$ In schoolchildren with asthma, lung function correlated negatively with serum hs-CRP, ${ }^{8}$ whereas in adolescents lung function, ${ }^{9}$ AHR, ${ }^{10}$ and serum vitamin D levels ${ }^{5}$ were not associated with hs-CRP. Neonatal lung function and plasma hs-CRP measured at 6 months of age correlated inversely. ${ }^{11}$

Because vitamin D might decrease low-grade systemic inflammation and protect young children from asthma, the aim of this study was to assess the incidence of vitamin D insufficiency and hsCRP-mediated systemic inflammation in infants with lower airway symptoms and to determine whether vitamin D insufficiency and increased serum hs-CRP might be linked to AHR in this population.

\section{Methods}

Patients

Seventy-nine consecutive infants with recurrent or persistent lower respiratory tract symptoms who were referred to a tertiary 
center from October 1, 2008 through September 28, 2011 were included in the present cross-sectional study. The study infants were 6 to 27 months old (median 15 months, interquartile range [IQR] 12-20 months) and underwent clinical examination, skin prick tests (SPTs), and peripheral blood sampling to determine blood eosinophil count and serum total immunoglobulin E (IgE), 25-hydroxyvitamin D (S-25-OHD), and hs-CRP. Comprehensive lung function testing included whole body plethysmography, measurements of tidal forced expirations with rapid thoracoabdominal compression, and a dosimetric bronchial methacholine challenge test. The medical history of the patients was charted by parental interviews using a structured questionnaire and a prospective review of the medical records.

The research ethics committee of the local university hospital approved the study. Written informed consent was obtained from the parents or legal guardians of the study children before any tests were performed or samples were drawn.

\section{Lung Function Tests and Bronchial Methacholine Challenge Test}

Lung function tests (eg, whole body plethysmography with rapid thoracoabdominal compression) were conducted as previously documented. ${ }^{12}$ To summarize briefly, the functional residual capacity (FRC) was determined with whole body plethysmography, ${ }^{12}$ and the maximal flow at FRC ( $\mathrm{V}_{\text {max,FRC }}^{\prime}$ ) was determined using the rapid thoracic compression technique, ${ }^{12}$ during which 3 acceptable maximal partial expiratory flow volume curves were recorded to calculate the mean $\mathrm{V}^{\prime}$ max,FRc. For the dosimetric bronchial methacholine challenge test, ${ }^{12}$ there were 2 end points in the challenge: a decrease of at least $40 \%$ in $\mathrm{V}^{\prime}$ max,FRC or reaching the maximal dose of methacholine. The provocative dose of methacholine causing a $40 \%$ decrease in $\mathrm{V}_{\text {max,FRC }}^{\prime}\left(\mathrm{PD} 40 \mathrm{~V}_{\text {max,FRC }}^{\prime}\right.$ ) was determined from the dose-response curves.

\section{Determining S-25-OHD and hs-CRP}

Serum S-25-OHD was measured on an Abbott Architect ci8200 analyzer (Abbott Laboratories, Abbott Park, Illinois) in the laboratory of the Genomics and Biomarkers Unit at the National Institute for Health and Welfare (Helsinki, Finland). The laboratory has been accredited by the Finnish Accreditation Service and it fulfils the requirements of the standards SFS-EN ISO/IEC 17025:2005. The method is a high-throughput automated chemiluminescent microparticle immunoassay (Architect 25-OH Vitamin D assay; Abbott Laboratories), which measures $25-\mathrm{OH}-\mathrm{D}_{2}$ and $25-\mathrm{OH}-\mathrm{D}_{3}$. For standardizing measurements, the laboratory has taken part in the Vitamin D External Quality Assessment Scheme organized by Imperial College Healthcare (National Health Service, London, United Kingdom). The coefficient of variation of the method (mean \pm SD) and systematic error (bias; mean \pm SD) were $3.6 \pm 1.5 \%$ and $-6.5 \pm 7.0 \%$, respectively. Serum samples for hs-CRP determination by immunoturbidimetric assay (CRPHS; Roche Diagnostics GmbH, Mannheim, Germany) were available from 63 infants. To minimalize the effect of a possible acute infection or inflammation, infants with hs-CRP levels of at least $10 \mathrm{mg} / \mathrm{L}$ were excluded, ${ }^{13}$ and hs-CRP results of the remaining 61 infants were included in the final analyses.

\section{Definitions}

Persistence or recurrence of lower airway symptoms was assessed in a parental interview using a structured questionnaire by a trained pediatrician. Atopic eczema was defined as a current diagnosis made by a pediatrician. ${ }^{12}$ SPT positivity was defined as a wheal with a diameter of at least $3 \mathrm{~mm}$ against at least 1 of the tested allergens. ${ }^{14}$ Blood eosinophilia was defined as an eosinophil count of at least $0.4 \times 10^{9} / \mathrm{L}$ and eosinophils composing at least $4 \%$ of leukocytes ${ }^{15}$ in peripheral blood. Atopy was defined as the presence of atopic eczema and/or SPT positivity. ${ }^{12}$ Vitamin D insufficiency was defined as an S-25-OHD concentration lower than $50 \mathrm{nmol} / \mathrm{L}$ (ie, $<20 \mathrm{ng} / \mathrm{mL}$ ). ${ }^{16}$ In the methacholine challenge, a PD40

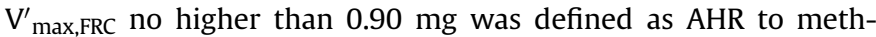
acholine and a value higher than $0.90 \mathrm{mg}$ was defined as no or mild responsiveness to methacholine. ${ }^{12}$ Increased hs-CRP was defined by the 75th percentile (hs-CRP $\geq 0.62 \mathrm{mg} / \mathrm{L}$ ).

\section{Statistical Methods}

A $\chi^{2}$ test or Fisher exact test (if the expected frequency for any cell was $<5$ ) was used for group comparisons of dichotomous variables. Mann-Whitney $U$ test or Kruskal-Wallis test was used to analyze continuous or ordinal variables, respectively. Correlations were determined using Spearman rank correlation test or Kendall $\tau$ statistics. Two-tailed tests were used in all analyses. A $P$ value less than .05 was considered statistically significant. The data were analyzed IBM SPSS Statistics 22 for Windows (IBM Corp, Armonk, New York).

\section{Results}

The baseline characteristics of the study infants included demographics, laboratory measurements related to atopy, and lung function parameters (Table 1). S-25-OHD levels varied from 27 to $121 \mathrm{nmol} / \mathrm{L}$ and were insufficient $(<50 \mathrm{nmol} / \mathrm{L})$ in $25 \%$ of infants and sufficient in $75 \%$ of infants.

S-25-OHD levels, vitamin D insufficiency, and increased hs-CRP levels (defined by the 75th percentile) were not associated with AHR to methacholine (PD40 $\mathrm{V}^{\prime}{ }_{\text {max,FRC }} \leq 0.90 \mathrm{mg}$ in bronchial methacholine challenge test) in infants with recurrent or persistent respiratory symptoms. In infants with AHR $(n=60)$, the median S-25-OHD level was $58 \mathrm{nmol} / \mathrm{L}$ (IQR 52-75 nmol/L), and in those

Table 1

Baseline Characteristics and Measurements in Study Infants

\begin{tabular}{|c|c|}
\hline Baseline characteristics $^{\mathrm{a}}$ & All infants $(\mathrm{N}=79$ \\
\hline Age (mo) & $15(12-20)$ \\
\hline BMI $\left(\mathrm{kg} / \mathrm{m}^{2}\right)$ & $17.0(1.4)$ \\
\hline Boys & $55(70)$ \\
\hline History of physician-diagnosed wheezing ( $\geq 1$ episode) & $50(63)$ \\
\hline Atopic eczema & $34(43)$ \\
\hline Positive SPT reaction ${ }^{c}$ & $21(27)$ \\
\hline Atopy $^{\mathrm{d}}$ & $42(53)$ \\
\hline Total IgE (kU/L) & $15(8-40)$ \\
\hline Blood eosinophil count $\left(\times 10^{9} / \mathrm{L}\right)$ & $0.25(0.17-0.38)$ \\
\hline Blood eosinophils (\%) & $3(2-4)$ \\
\hline Blood eosinophilia ${ }^{\mathrm{e}}$ & $16(20)$ \\
\hline \multicolumn{2}{|l|}{ Lung function parameters } \\
\hline FRC $z$-score & $1.0(1.2)$ \\
\hline FRC $z$-score $\geq 2$ SD & $18(23)$ \\
\hline $\mathrm{V}_{\text {max,FRC }}^{\prime} z$-score & $-0.7(1.0)$ \\
\hline $\mathrm{V}_{\max , \mathrm{FRC}}^{\prime} z$-Score $\leq-2 \mathrm{SD}$ & $9(11)$ \\
\hline \multicolumn{2}{|l|}{ Methacholine challenge test } \\
\hline PD40 V' ${ }_{\text {max,FRC }}(\mathrm{mg})$ & $0.35(0.19-0.80)$ \\
\hline$\leq 0.90 \mathrm{mg}$ & $60(76)$ \\
\hline $\mathrm{S}-\overline{25}-\mathrm{OHD}(\mathrm{nmol} / \mathrm{L})$ & $59(49-71)$ \\
\hline$<50 \mathrm{nmol} / \mathrm{L}$ & $20(25)$ \\
\hline hs-CRP (mg/L) & $0.12(0.02-0.62)$ \\
\hline
\end{tabular}

Abbreviations: BMI, body mass index; FRC, functional residual capacity; hs-CRP high-sensitivity C-reactive protein; IgE, immunoglobulin E; PD40 V' $\mathrm{V}_{\text {max,FRC, dose of }}$ methacholine causing 40\% decrease in maximal expiratory flow at functional residual capacity; S-25-OHD, serum 25-hydroxyvitamin D; SPT, skin prick test;

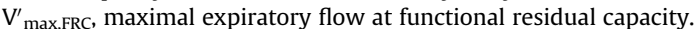

${ }^{a}$ Data are presented as mean (SD), median (interquartile range), or number (percentage).

${ }^{\mathrm{b}}$ Diagnosed by a pediatrician.

${ }^{\mathrm{c}} \mathrm{A}$ wheal of at least $3 \mathrm{~mm}$ compared with any of the tested allergens.

${ }^{\mathrm{d}}$ Atopic eczema and/or positive SPT reaction.

ePeripheral blood eosinophil count of at least $0.4 \times 10^{9} / \mathrm{L}$ and percentage of at least $4 \%$ of total leukocytes. 
without AHR $(\mathrm{n}=19)$, the median S-25-OHD level was $65 \mathrm{nmol} / \mathrm{L}$ (IQR 51-76 nmol/L; $P=.226$ ). Vitamin D insufficiency was detected in 17 infants (28\%) with AHR and 3 infants (16\%) without AHR $(P=.371)$. Increased hs-CRP was detected in 12 infants (26\%) with AHR and 12 infants $(80 \%)$ without AHR $(P=.742)$.

Similarly, vitamin D insufficiency was not associated with the presence of respiratory symptoms or baseline lung function (data not shown). The infants with blood eosinophilia (eosinophil count $\geq 0.4 \times 10^{9} / \mathrm{L}$ and eosinophils composing $\geq 4 \%$ of leukocytes) and with documented AHR had significantly lower S-25-OHD levels than those without these characteristics (Fig 1). Moreover, vitamin D insufficiency was most common in this subgroup (Fig 2).

Serum hs-CRP was lower in infants with recurrent ( $\geq 3$ episodes) physician-diagnosed wheezing (median $0.02 \mathrm{mg} / \mathrm{L}$, IQR $0.02-0.12$ $\mathrm{mg} / \mathrm{L}, \mathrm{n}=9$ ) than in those without (median $0.16 \mathrm{mg} / \mathrm{L}$, IQR $0.05-0.63 \mathrm{mg} / \mathrm{L}, \mathrm{n}=51 ; P=.048)$. Similarly, hs-CRP was lower in those infants with blood eosinophilia (median $0.06 \mathrm{mg} / \mathrm{L}, \mathrm{IQR}$ $0.02-0.11 \mathrm{mg} / \mathrm{L}, \mathrm{n}=13$ ) than in those without (median $0.18 \mathrm{mg} / \mathrm{L}$, IQR $0.05-0.74 \mathrm{mg} / \mathrm{L}, \mathrm{n}=48 ; P=.015$ ). Neither S-25-OHD nor hs-CRP correlated with age, body mass index, IgE, blood eosinophil count or percentage, baseline lung function, AHR (Table 2), or each other $\left(\tau_{\mathrm{B}}=0.080, P=.382\right)$, and they were not associated with sex, atopic eczema, or SPT positivity (data not shown).

S-25-OHD concentration was significantly lower (median 54 $\mathrm{nmol} / \mathrm{L}$, range $27-106 \mathrm{nmol} / \mathrm{L}$ ) during the autumn-winter season (October to March) than during the spring-summer season (April to September; median $63 \mathrm{nmol} / \mathrm{L}$, range 45-121 nmol/L; $P=.026)$. There was no such seasonal variation in hs-CRP (data not shown).

When stratifying the analyses by the season of the year, a negative correlation emerged between S-25-OHD concentration and blood eosinophil percentage $\left(r_{\mathrm{s}}=-0.348, P=.015\right)$ in the samples obtained during the autumn-winter season. Similarly, in samples obtained during the autumn-winter season, vitamin D insufficiency was much more prevalent in infants with blood eosinophilia and AHR $(\mathrm{n}=5$ of $6,83 \%)$ than in other infants $(\mathrm{n}=12$ of $42,29 \%$; $P=.017)$.

\section{Discussion}

Although in Finland the use of vitamin D supplementation is advised for all children throughout the year, vitamin D insufficiency was common in infants with troublesome lung symptoms, particularly in those with blood eosinophilia and AHR. In contrast, increased hs-CRP levels were rare in wheezy infants and were not associated with vitamin D status, blood eosinophilia, or AHR.

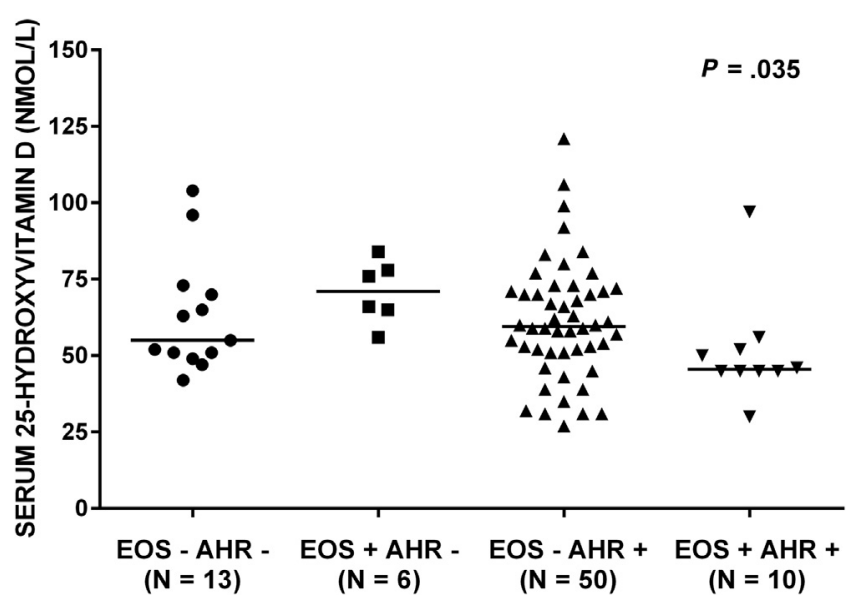

Figure 1. Serum 25-hydroxyvitamin D concentration (median indicated with horizontal line) was lowest in symptomatic infants with blood eosinophilia $\left(\mathrm{EOS}^{+}\right)$ and airway hyperresponsiveness $\left(\mathrm{AHR}^{+}\right)$compared with others.

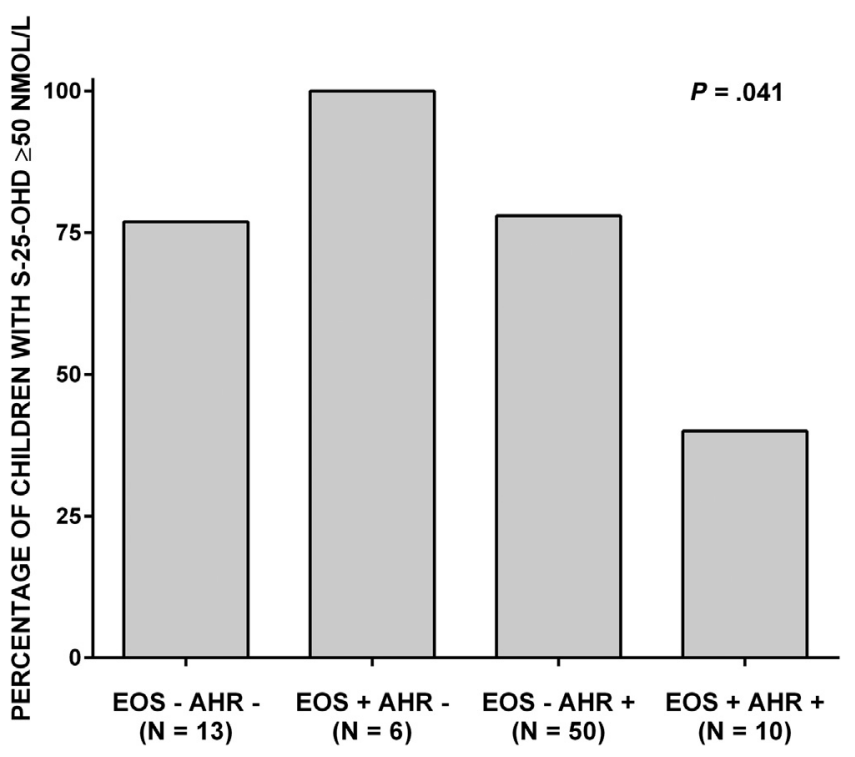

Figure 2. Vitamin D insufficiency (25-hydroxyvitamin $D<50 \mathrm{nmol} / \mathrm{L}$ ) was most common in symptomatic infants with blood eosinophilia $\left(\mathrm{EOS}^{+}\right)$and airway hyperresponsiveness $\left(\mathrm{AHR}^{+}\right)$compared with others.

Consistent with a previous report from Finland, ${ }^{17}$ vitamin D insufficiency was observed in one fourth of infants with recurrent or persistent respiratory symptoms and was associated with the dark and cold half of the year. The inverse association between S25-OHD level and age might indicate that the use of vitamin D supplementation becomes more irregular as the children grow older. $^{17}$

Although the role of vitamin D in asthma is not fully established, vitamin D insufficiency has been linked with worse asthma control, more exacerbations, and emergency department visits in adults ${ }^{1}$ and children with asthma. ${ }^{1,6,18}$ In recurrent preschool wheezers, vitamin $\mathrm{D}$ insufficiency has been associated with frequent exacerbations requiring oral corticosteroids, ${ }^{6}$ and oral supplementation of vitamin D might lessen exacerbations during treatment of lower airway symptoms with inhaled corticosteroids. ${ }^{19}$ In adults and children with asthma, vitamin D levels and vitamin D insufficiency have been associated with decreased lung function. ${ }^{1,2,20}$ Moreover, schoolchildren with asthma and AHR have been found to have lower vitamin D levels than their peers without AHR. ${ }^{3,4}$ In contrast, in a recent report of schoolchildren with asthma, vitamin D levels showed no correlation with AHR or lung function. ${ }^{5}$ These findings

Table 2

Correlations Among S-25-OHD, hs-CRP, and Other Continuous Baseline Data

\begin{tabular}{|c|c|c|c|c|}
\hline \multirow[t]{2}{*}{ Baseline measurements } & \multicolumn{2}{|c|}{ S-25-OHD (N = 79) } & \multicolumn{2}{|c|}{ hs-CRP ( $N=61)$} \\
\hline & $\mathrm{r}_{\mathrm{s}}$ & $P$ value & $\tau_{\mathrm{B}}$ & $P$ value \\
\hline Age & 0.026 & .819 & 0.103 & .255 \\
\hline BMI & 0.016 & .886 & -0.009 & .920 \\
\hline Total IgE & -0.108 & .343 & 0.088 & .333 \\
\hline Blood eosinophil count & -0.161 & .157 & -0.083 & .365 \\
\hline Blood eosinophil percentage & -0.181 & .110 & -0.053 & .555 \\
\hline FRC $z$-score & 0.109 & .340 & -0.022 & .811 \\
\hline $\mathrm{V}_{\text {max,FRC }}^{\prime} Z$-score & 0.047 & .679 & -0.073 & .428 \\
\hline PD40 V' ${ }_{\text {max }, F R C}$ & 0.078 & .495 & 0.080 & .381 \\
\hline
\end{tabular}

Abbreviations: BMI, body mass index; FRC, functional residual capacity; hs-CRP,

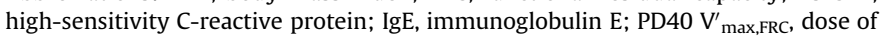
methacholine causing $40 \%$ decrease in maximal expiratory flow at functional residual capacity; $r_{s}$, Spearman rank correlation coefficient; S-25-OHD, 25-hydroxyvitamin $\mathrm{D}$; $\mathrm{V}_{\text {max,FRC, maximal expiratory flow at functional residual }}^{\prime}$ capacity; $\tau_{\mathrm{B}}$, Kendall $\tau$-b coefficient. 
are in accordance with our results, because they do not suggest a strong and clear association between low vitamin D levels and wheezing or decreased lung function. Interestingly, however, in our study, the S-25-OHD levels were low in a subgroup of infants with blood eosinophilia and AHR.

The children with high prenatal maternal vitamin D intake had a decreased risk of recurrent wheezing in early childhood. ${ }^{18}$ Similarly, cord blood vitamin D was inversely associated with the risk of respiratory infections at 3 months of age and with the risk of wheezing from 15 months to 5 years of age. ${ }^{18}$

Animal studies have indicated that vitamin D stimulates type II alveolar cell maturation and airway alveolarization, ${ }^{21}$ and therefore vitamin D deficiency might alter the airway maturation and predispose to adverse respiratory outcomes. Moreover, vitamin D might inhibit the postnatal inflammatory response and the resulting epithelial injury during viral infections, ${ }^{1}$ the underlying causes of early childhood wheeze. These findings support our conclusion that vitamin D insufficiency might modify the airways in symptomatic infants with blood eosinophilia and AHR.

Vitamin D insufficiency did not promote hs-CRP-mediated lowgrade systemic inflammation. This is supported by previous findings demonstrating that eosinophilic inflammation and remodeling of the airways are rare during the first 2 years of life $\mathrm{e}^{22}$ and that the association between a thickening of bronchial reticular basement membrane and eosinophilic bronchial inflammation appears later in childhood. ${ }^{23}$ Because the children in our study were younger than 3 years, the inflammatory process could still be subclinical, explaining in part the low hs-CRP levels.

In contrast to our results, oral vitamin D supplementation as a sole therapy for mild asthma has failed to affect AHR or allergic inflammation. ${ }^{24}$ This might reflect the heterogeneity of asthma in different age groups. Similarly, the heterogeneity of early childhood respiratory symptoms could explain why in our study S-25-OHD was significantly lower only in a subgroup of symptomatic infants with blood eosinophilia and AHR, and no such difference emerged when comparing all infants with AHR and those without it.

Although the final sample size was rather small, all patients underwent comprehensive lung function tests with standardized techniques. We also measured S-25-OHD from peripheral blood, instead of relying on parental interviews or intake calculations, and thus minimized the risk of reporting bias. The study patients were recruited from a tertiary clinic and thus more often presented severe symptoms, and the results cannot be generalized to the entire population of early childhood wheezers. Moreover, the crosssectional study design did not allow an evaluation of the importance of our findings for the risk of developing asthma, an issue that is to be resolved in future follow-up studies.

We conducted an observational pilot study to evaluate the relation between vitamin D insufficiency and AHR to methacholine in infants with troublesome lung symptoms. Because the normal distribution of the variable PD40 $\mathrm{V}_{\text {max, }}^{\prime} \mathrm{FRC}$ is not known in children younger than 3 years, and the incidence of vitamin $D$ insufficiency defined as an S-25-OHD concentration lower than $50 \mathrm{nmol} / \mathrm{L}$ varies greatly among different populations and age groups, we could not reliably estimate statistical power before commencing the study. Nevertheless, in post hoc analyses based on recent information on vitamin D insufficiency and its relation to asthmatic symptoms in children, the estimated power ranged from $28 \%^{5,25}$ to $79 \%{ }^{26,27}$ With a more stringent study participant selection based on vitamin D insufficiency and degree of AHR, our results could have been strengthened.

Larger cross-sectional studies are still required to fully elicit the role of vitamin D insufficiency and AHR in infants with recurrent or persistent lower airway symptoms. In future, randomized controlled intervention studies with a long-term follow-up also could evaluate whether sufficient S-25-OHD levels acquired by oral vitamin D supplementation might decrease the risk of future asthma in early childhood wheezers.

In conclusion, vitamin D insufficiency might underlie eosinophilia and AHR in infants with troublesome lung symptoms, whereas hs-CRP-mediated low-grade systemic inflammation is rare in early childhood wheezing.

\section{Acknowledgments}

We thank Tuija Rito, RN, for her skill in tending the study children, as well as the children and their families.

\section{References}

[1] Jiao J, Castro M. Vitamin D and asthma: current perspectives. Curr Opin Allergy Clin Immunol. 2015;15:375-382.

[2] Yao TC, Tu YL, Chang SW, et al. Serum 25-hydroxyvitamin D levels in relation to lung function and exhaled nitric oxide in children. J Pediatr. 2014;165: 1098-1103.e1.

[3] Brehm JM, Celedón JC, Soto-Quiros ME, et al. Serum vitamin D levels and markers of severity of childhood asthma in Costa Rica. Am J Respir Crit Care Med. 2009;179:765-771.

[4] Chinellato I, Piazza M, Sandri M, et al. Serum vitamin D levels and exerciseinduced bronchoconstriction in children with asthma. Eur Respir J. 2011;37: 1366-1370.

[5] Dabbah H, Bar Yoseph R, Livnat G, Hakim F, Bentur L. Bronchial reactivity, inflammatory and allergic parameters, and vitamin D levels in children with asthma. Respir Care. 2015;60:1157-1163.

[6] Beigelman A, Zeiger RS, Mauger D, et al. The association between vitamin D status and the rate of exacerbations requiring oral corticosteroids in preschool children with recurrent wheezing. J Allergy Clin Immunol. 2014;133: 1489-1492. 1492.e1-e3.

[7] Chen N, Wan Z, Han SF, Li BY, Zhang ZL, Qin LQ. Effect of vitamin D supplementation on the level of circulating high-sensitivity C-reactive protein: a meta-analysis of randomized controlled trials. Nutrients. 2014;6:2206-2216.

[8] Deraz TE, Kamel TB, El-Kerdany TA, El-Ghazoly HM. High-sensitivity C reactive protein as a biomarker for grading of childhood asthma in relation to clinical classification, induced sputum cellularity, and spirometry. Pediatr Pulmonol. 2012;47:220-225.

[9] Nybo M, Hansen HS, Siersted HC, Rasmussen F. No relationship between lung function and high-sensitive C-reactive protein in adolescence. Clin Respir J. 2010;4:230-236.

[10] Livnat G, Yoseph Bar R, Nir V, Hakim F, Yigla M, Bentur L. Evaluation of high sensitivity serum CRP levels compared to markers of airway inflammation and allergy as predictors of methacholine bronchial hyper-responsiveness in children. Lung. 2015;193:39-45.

[11] Chawes BL, Stokholm J, Bønnelykke K, Brix S, Bisgaard H. Neonates with reduced neonatal lung function have systemic low-grade inflammation. J Allergy Clin Immunol. 2015;135:1450-1456.e1.

[12] Kotaniemi-Syrjänen A, Malmberg LP, Pelkonen AS, Malmström K, Mäkelä MJ. Airway responsiveness: associated features in infants with recurrent respiratory symptoms. Eur Respir J. 2007;30:1150-1157.

[13] Schlenz H, Intemann T, Wolters M, et al. C-reactive protein reference percentiles among pre-adolescent children in Europe based on the IDEFICS study population. Int J Obes. 2014;38(suppl 2):S26-S31.

[14] Anonymous position paper: Allergen standardization and skin tests. The European Academy of Allergology and Clinical Immunology. Allergy. 1993;48: 48-82.

[15] Guilbert TW, Morgan WJ, Zeiger RS, et al. Atopic characteristics of children with recurrent wheezing at high risk for the development of childhood asthma. J Allergy Clin Immunol. 2004;114:1282-1287.

[16] Misra M, Pacaud D, Petryk A, Collet-Solberg PF, Kappy M; Drug and Therapeutics Committee of the Lawson Wilkins Pediatric Endocrine Society. Vitamin D deficiency in children and its management: review of current knowledge and recommendations. Pediatrics. 2008;122:398-417.

[17] Koistinen A, Turunen R, Vuorinen T, et al. Vitamin D, virus etiology, and atopy in first-time wheezing children in Finland. Pediatr Allergy Immunol. 2014;25: $834-837$.

[18] Comberiati P, Tsabouri S, Piacentini GL, Moser S, Minniti F, Peroni DG. Is vitamin D deficiency correlated with childhood wheezing and asthma? Front Biosci (Elite Ed). 2014;6:31-39.

[19] Riverin BD, Maguire JL, Li P. Vitamin D supplementation for childhood asthma: a systematic review and meta-analysis. PLoS One. 2015;10:e0136841.

[20] Sandhu MS, Casale TB. The role of vitamin D in asthma. Ann Allergy Asthma Immunol. 2010;105:191-199.

[21] Lykkedegn S, Sorensen GL, Beck-Nielsen SS, Christesen HT. The impact of vitamin D on fetal and neonatal lung maturation. A systematic review. Am Physiol Lung Cell Mol Physiol. 2015;308:L587-L602. 
[22] Saglani S, Malmström K, Pelkonen AS, et al. Airway remodeling and inflammation in symptomatic infants with reversible airflow obstruction. Am J Respir Crit Care Med. 2005;171:722-727.

[23] Saglani S, Payne DN, Zhu J, et al. Early detection of airway wall remodeling and eosinophilic inflammation in preschool wheezers. Am J Respir Crit Care Med. 2007; 176:858-864.

[24] Bar Yoseph R, Livnat G, Schnapp Z, et al. The effect of vitamin D on airway reactivity and inflammation in asthmatic children: A double-blind placebocontrolled trial. Pediatr Pulmonol. 2015;50:747-753.
[25] Viljakainen HT, Korhonen T, Hytinantti T, et al. Maternal vitamin D status affects bone growth in early childhood-a prospective cohort study. Osteoporos Int. 2011;22:883-891.

[26] Turkeli A, Ayaz O, Uncu A, et al. Effects of vitamin D levels on asthma control and severity in pre-school children. Eur Rev Med Pharmacol Sci. 2016;20: 26-36.

[27] Østergård M, Arnberg K, Michaelsen KF, et al. Vitamin D status in infants: relation to nutrition and season. Eur J Clin Nutr. 2011;65 $657-660$. 